\title{
Serbest Zaman Engelleri ile Engellerle Baş Etme Stratejileri arasındaki İlişkinin İncelenmesi: Keşifsel Bir Çalışma*
}

\section{Investigation of the Relationship between Leisure Constraints and Negotiation Strategies: An Exploratory Study}

\author{
ORİJINAL ARAŞTIRMA/ \\ ORIGINAL RESEARCH \\ Tennur Yerlisu Lapa ${ }^{1 \dagger}$ \\ Elif Köse ${ }^{2}$
}

\author{
${ }^{1}$ Akdeniz Üniversitesi, Spor Bilimleri \\ Fakültesi, Antalya. \\ http://orcid.org/0000-0002-8647-1473 \\ ${ }^{2}$ Akdeniz Üniversitesi, Sağlık Bilimleri \\ Enstitüsü, Spor Bilimleri Anabilim Dalı, \\ Antalya. \\ http://orcid.org/0000-0002-5490-3534
}

\begin{abstract}
Öz
Bu çalışmanın amacı serbest zaman engelleri ile serbest zaman engelleri ile baş etme stratejileri arasındaki ilişkiyi incelemektir. Araştırmanın evreni Akdeniz Üniversitesinde okuyan üniversite öğrencilerinden oluşurken, araștırma örneklemi ise Akdeniz Üniversitesinde okuyan 386 üniversite öğrencisinden oluşturmaktadır. Araştırmada örneklem seçimi yöntemi olarak kolayda örnekleme yöntemi kullanılmıştır. Veri toplamak amacıyla Beggs ve ark. tarafindan son hale getirilmiş ve Yerlisu Lapa tarafından Türkçeye adapte edilmiş "Serbest Zaman Engelleri ile Baş Etme Stratejileri Ölçeği” ile Alexandris ve Carroll tarafindan geliştirilen ve Karaküçük ve Gürbüz tarafından Türkçeye adapte edilen ve yine Gürbüz ve ark. tarafından yapı geçerliği sınanan "Boş Zaman Engelleri Ölçeği”nin kısa formu kullanılmıştır. Araştırma bulguları incelendiğinde; serbest zaman engelleri olarak tanımlanan $\mathrm{U}_{1}$ kanonik değişkenine en önemli katkıların .75 ile tesis/hizmet/ulaşım, .73 ile zaman eksikliği ve .67 ile sosyal ortam sağlamaktadır. Serbest zaman engelleri ile baş etme stratejileri olarak tanımlanan $V_{1}$ kanonik değişkenine en önemli katkının ise .73 ile fiziksel uygunluk stratejilerinin olduğu görülmektedir. $V_{1}$ kanonik değişkenine katkı sağlayan diğer değişkenleri ise sırasıyla; .66 ile beceri stratejileri, .62 ile finansal yönetim, .59 ile zaman yönetimi stratejileridir. Sonuç olarak, serbest zaman engelleri kümesinin varyansının \%9.70'i serbest zaman engelleri ile baş etme stratejileri tarafindan açıklanırken, serbest zaman engelleri ile bas etme stratejileri kümesinin \%10.41'inin serbest zaman engelleri kanonik değişkeni tarafından açıklandığı görülmektedir.
\end{abstract}

Anahtar Kelimeler: Serbest Zaman Engelleri, Serbest Zaman Baş Etme Stratejileri, Kanonik Korelasyon Analizi

\begin{abstract}
The aim of this study is to investigate the association between the leisure constraints and the negotiation strategies with the leisure constraints. The research population of this study is the students of Akdeniz University, while the research sample consists of 386 students attending Akdeniz University. Convenience sampling method is chosen for sampling of this study. "Leisure Negotiation Strategies Scale" finalized by Beggs et al. and adapted into Turkish by Yerlisu Lapa was used for data gathering purposes; together with the short form of "Leisure Constraints Questionnaire" developed by Alexandris and Carroll and adapted to Turkish by Karaküçük and Gürbüz, who also tested the scale for construct validity. Examining the research findings, it is observed that the most significant contributions to the $U_{1}$ canonical variate come from .75 facilities/services \& accessibility, .73 time and .67 social environment. The most significant contribution to the $\mathrm{V}_{1}$ canonical variate that is defined as the leisure constraints coping strategies comes from the .73 physical fitness strategies. Other variates that contribute to the $\mathrm{V}_{1}$ canonical variate are .66 skill-acquisition, .62 financial management and .59 time management strategies, respectively. In conclusion, it is discovered that $9.70 \%$ of the variance of leisure constraints cluster is explained by the leisure constraints negotiation strategies; whereas $10.41 \%$ of the variance of leisure constraints negotiation strategies cluster is explained by the canonical variate of leisure constraints.
\end{abstract}

Key Words: Leisure Constraints, Negotiation Strategies, Canonical Correlation Analysis

\footnotetext{
* Bu çalışma 10-13 Mayıs 2018 tarihleri arasında Muğla/Bodrum'da yapılan Uluslararası Rekreasyon ve Spor Yönetimi Kongresinde poster bildiri olarak sunulmuştur.

$\dagger$ Sorumlu yazar: Tennur Yerlisu Lapa, tennur@akdeniz.edu.tr
} 


\section{GİRIŞ}

Teknolojik gelişmeler bireylerin çalışma saatlerinde azalmaya buna bağlı olarak serbest zamanlarında artışa sebep olmuştur. Bu durum serbest zaman katılımı ve serbest zamana katılım sorunsalı üzerindeki ilgiyi de arttırmıştır. Bu nedenle son 30 yıldır serbest zamana katılımı etkileyen unsurlar üzerinde yapılan çalışmaların önem kazandığı ve günümüzde de ilgi odağı olan konular arasında olduğu görülmektedir. Bu ilgi odağının temelinde sosyal ve fiziksel olarak aktif olan insanın hem fiziksel hem de psikolojik olarak daha sağlıklı olduğuna yönelik bulgular yatmaktadır. Serbest zamanın birey üzerindeki olumlu etkileri serbest zamanın temel fonksiyonları üzerinden ifade edilmektedir. Örneğin Torkildsen (2005), gündelik hayat stresinin insanların hem psikolojik hem de fiziksel açıdan zarar görmesine neden olduğu ancak serbest zaman deneyimlerinin bireyleri rahatlatmak ve yenilemek işlevi ile bu zararları bertaraf ettiğini ifade etmektedir. Bununla birlikte farklı beceriler, ilgi alanları, hobiler edinerek kendilerini geliştirdikleri, sosyal dayanışma üzerinde de etkileri olduğu dolayısı ile kişilerarası ilişkileri geliştirdiği de alanyazında anlatılan hususlar arasındadır. İnsan hayatını hem fiziksel hem psikolojik hem de sosyal açıdan bu kadar olumlu etkileyen serbest zaman aktivitelerine katılım ise birçok faktör tarafından etkilenmektedir. Alanyazın incelendiğinde serbest zaman katımını, serbest zaman motivasyonu, serbest zaman kolaylaştırıcıları, serbest zaman engelleri, serbest zaman engelleri ile baş etme stratejileri ve serbest zaman tutumu gibi birçok faktörün etkilediği görülmektedir (Hubbard ve Mannell, 2001; Kim, Heo, Chun, \& Lee, 2011; Raymore, 2002). Ancak bu çalışmanın odak noktası serbest zaman engelleri ve bu engeller ile baş etme stratejileri arasındaki ilişkidir. Ulusal ve uluslararası alanyazın incelendiğinde serbest zaman engelleri ve bu engeller ile baş etme stratejileri arasındaki ilişkiler ve serbest zaman katılımını nasıl düzeyde etkiledikleri ele alınmış olsa da; keşifsel bir çalışma olarak bu iki değişken arasındaki ilişkinin ele alındığı herhangi bir çalışmanın olmadığı görülmektedir. Yapılan çalışmanın asıl amacı, bireylerin hangi engeller karşısında hangi baş etme stratejilerini geliştirdiğini anlamaktır. Rastgele seçilmiş bir hipotez testi yerine değişkenler arasındaki başat değişkenleri ele almanın, bu iki değişken arasındaki ilişkinin daha ayrıntılı bir şekilde incelenmesine olanak tanıdığı düşünülmektedir. Bu yönü ile alanyazındaki boşluğu dolduracağı ifade edilebilir. 


\section{Serbest Zaman Engelleri ve Engeller ile Baş Etme Stratejileri}

Engel, bir bireye ilişkin soyut veya somut, bir veya birden fazla olumsuz faktörün bir araya gelmesi ile motivasyonunun olumsuz anlamda etkilenmesi ve bu nedenle rekreatif bir faaliyete katılmaması veya katılım sıklığının azalması olarak tanımlanabilir (Jackson, 1988). Engellere ilişkin ilk ortaya çıkan kuram Crawford ve Godbey (1987)’ye aittir. Onlara göre engeller, bireylerin kendisinden kaynaklı olan psikolojik durumlarla ilişkili içsel, farklı bireylerin birbiri ile ilgili çatışmalarına dayalı kişilerarası ve tesis ve ulaşım gibi yapıları kapsayan yapısal engeller olmak üzere üç temel engelden oluşmaktaydı. Alexandris ve Carroll (1997) içsel ve dişsal engeller olmak üzere engelleri iki ana başlık altında toplamışlardır. Bununla birlikte serbest zaman engellerini tanımlamanın, serbest zaman katılımını hem daha iyi planlamak hem de daha kaliteli bir organizasyon yapmak için önemli olduğu görülmektedir (Jackson, 1988).

Serbest zaman katılımını etkileyen bir diğer önemli unsur ise serbest zaman engelleri ile baş etme stratejileridir. Herhangi bir etkinliğe katılmak için engeller olabilir ancak bazı bireyler bu engelleri aşarak istedikleri etkinliklere katılım sağlayabilmiştirler. Jackson (1993) göre; bir etkinliğe katılımda önemli rol oynadığı düşünülen engeller, aslında bireylerin o etkinliğe katılımları üzerinde etkin bir rol oynamamaktadır. Bu durum serbest zaman engelleri ile baş etme kuramının oluşmasında önemli bir rol oynamıştır (Jackson ve Rucks, 1995; Hubbard ve Mannell, 2001). Baş etme genel olarak; bir bireyin serbest zamanda bir etkinliğe katılmak için karşılaşmış olduğu engellerle düzenli bir şekilde baş edebilme ve bu engelleri aşma, azaltma veya adapte olma yeteneğidir (Crawford, Jackson ve Godbey, 1991; Scott, 1991). Bu yetenek bireyler için herhangi bir engel ile karşılaştıklarında nasıl baş edebilecekleri hususunda önemli ipuçları sağlayan ve insan hayatı için oldukça önemli bir konu olarak karşımıza çıkmaktadır (Henderson ve Bialeschki, 1993; Samdahl ve Jekubovich, 1997; Little, 2000). Serbest zaman engelleri ile baş etme stratejileri ilk kez Jackson, Crawford ve Godbey (1993) tarafından ortaya konulmuştur. Jackson ve ark. (1993) göre serbest zaman engelleri ile baş etme stratejileri kuramsal olarak ikiye ayrılmaktadır. Bu kuramsal yapıya göre serbest zaman engelleriyle baş etme stratejileri bilişsel (içsel) ve davranışsal (yapısal ve kişiler arası) olarak ifade edilmektedir. Daha açık bir şekilde ifade edilecek olunursa; içsel onaylama, bilişsel baş etme stratejileri arasında görülürken; zaman yönetimi, beceri edinimi, kişiler arası ilişkiler, finansal yönetim ve fiziksel uygunluk stratejileri, davranışsal baş etme stratejileri arasında görülmektedir (Jackson, 1995). Serbest zaman engelleri ile baş etme stratejileri 
üzerine çalışan diğer araştırmacılar da bu kuramsal alt yapıyı destekleyen çalışmalar yapmışlardır (Elkins, 2004; Hubbard ve Mannell, 2001).

Uluslararası alanyazını incelendiğinde serbest zaman katılımında belirleyici olduğu düşünülen bu iki kavramdan serbest zaman engellerine ilişkin çalışmaların daha çok kadınların engellerine (Henderson, 1991; Henderson ve Dialeschki, 1991; Shaw, Bonen \& McCabe, 1991; Shaw, 1994), fiziksel aktivite engellerine (Dishman, Sallis \& Orenstein, 1985; Pinto, Marcus \& Clark, 1996) odaklandığı görülürken; serbest zaman engelleri ile baş etme stratejilerine yönelik çalışmaların ise açık alan rekreasyonu (Alexandris Kouthouris ve Girgolas, 2007; Coble, Selin ve Erickson, 2003; Jackson ve Rucks, 1995; Stanis, Schneider, Chavez ve Shinew, 2009; White, 2008), engelli bireyler (Henderson, Bedini, Hecht ve Schuler, 1995) kadınlar ve bunların içinde farklı dine mensup ve farklı cinsel yönelimi olan kadınlara (Bialeschki ve Pearce, 1997; Koca, Henderson, Asci ve Bulgu, 2009; Son, Mowen ve Kerstetter, 2008a;) ve öğrencilere (Elkins, Beggs ve Choutka, 2007; Ma, Tan \& Ma, 2002) odaklanıldığı görülmektedir.

Ülkemizde yapılan çalışmalara bakıldığında ise engellere ilişkin çalışmaların; kamu çalışanları (Çakır, Şahin, Serdar \& Parlakkılıç 2016), gençler (Özşaker, 2012), kadınlar (Güner, 2015) ve bununla birlikte özellikle sağlık çıktıları nedeniyle fiziksel aktivite engellerine yönelik olduğu görülmektedir (Gümüş, Işık, Karakullukçu ve Yıldırım, 2014). Yine serbest zaman fiziksel aktivite engellerine ilişkin çalışmaların yoğunlaştığı bir başka grup da dezavantajlı olarak görülen suçlu bireylerdir. Özellikle bu gruba yönelik çalışmalara karşı ilginin arttığı da söylenebilir (Köse, 2018; Köse ve Yerlisu Lapa, 2018). Engeller ile baş etme stratejilerine ilişkin alanyazın tarandığında ise çalışmaların çok sınırlığı olduğu, olan çalışmaların ise üniversite öğrencileri ve cinsiyete odaklandığı görülmektedir (Karaca ve Yerlisu Lapa, 2016; Yerlisu Lapa ve Haşıl Korkmaz, 2017).

Serbest zaman engelleri ve baş etme stratejileri serbest zamana katılım açısından oldukça önemli iki unsur olarak bilinmektedir. Birbirleriyle yakından ilişkili olan bu iki kavrama ilişkin; serbest zaman engellerinin artması ile katılımın azaldığı ancak bireylerin katılım sağlamaya yönelik baş etme stratejilerini arttırdığını ortaya koymaktadır (Hubbard ve Mannell, 2001). Ulusal ve uluslararası çalışmaların bir kısmı farklı değişkenlere göre engeller ve baş etme stratejileri arasında fark olup olmadığını saptamaya çalışırken, diğer kısmı ise özellikle dezavantajı olarak bilinen (kadınlar, engelli bireylerin vb.) bireylerin karşılaştığı engeller ve bu engeller ile nasıl 
mücadele ettiklerine yönelik uygulamaları nitel araştırma yöntemleri ile ele almıştır (Henderson ve ark., 1995; Little, 2002; Livengood ve Stodolska, 2004).

\section{Kanonik Korelasyon Analizi}

Alanyazın bölümünde bahsedilen çalışmalara karşın keşfedici bir çalışma olan ve rastgele seçilmiş bir hipotez testinden daha fazla fayda elde edebilen Kanonik Korelasyon Analizi (KKA) ile ilgili bir çalışma neredeyse bulunmamaktadır. Bu çalışmada KKA' nin tercih edilmesinin sebebi ise serbest zaman engelleri ve baş etme stratejileri arasındaki ilişki ve başat değişkenlerin tespitine yönelik bir analizin bu iki kavram arasındaki ilişkiyi daha anlaşılır bir şekilde ortaya koyacak olmasıdır. Bununla birlikte keşfedici olarak anılan bu çalışma, yalnızca bağımsız değişkenin bağımlı değişkeni ne kadar açıkladığı değil, aynı zamanda bağımlı değişkenin bağımsız değişkeni de ne kadar açıkladığını ortaya koyması nedeniyle (Temurtaş, 2016) önemlidir. KKA her biri orijinal değişkenlerin ağırlıklı kombinasyonunu temsil eden iki değişken arasındaki korelasyonu maksimize eder (Kachigan, 1991). KKA'da öncelikli amaç birim varyanslı olup birbirinden bağımsız kanonik değişkenler arasında kanonik fonksiyonlar elde etmektedir. Doğrusal bileşenler arasında maksimize edilen korelasyonlar aracılığıyla oluşturulan her bir fonksiyon bir değişken çiftine sahiptir (Hair, Black, Babin ve Anderson, 1998). Bununla birlikte KKA'nın tercih edilmesinde; ölçme işlemine karışabilecek I. Tip hatayı kontrol altına almaya olanak tanımasıyla ve bu nedenle gerçekte anlamlı olmayan ilişkilerin anlamlı kabul edilmesi olasılığını azaltması önemli bir rol oynamaktadır.

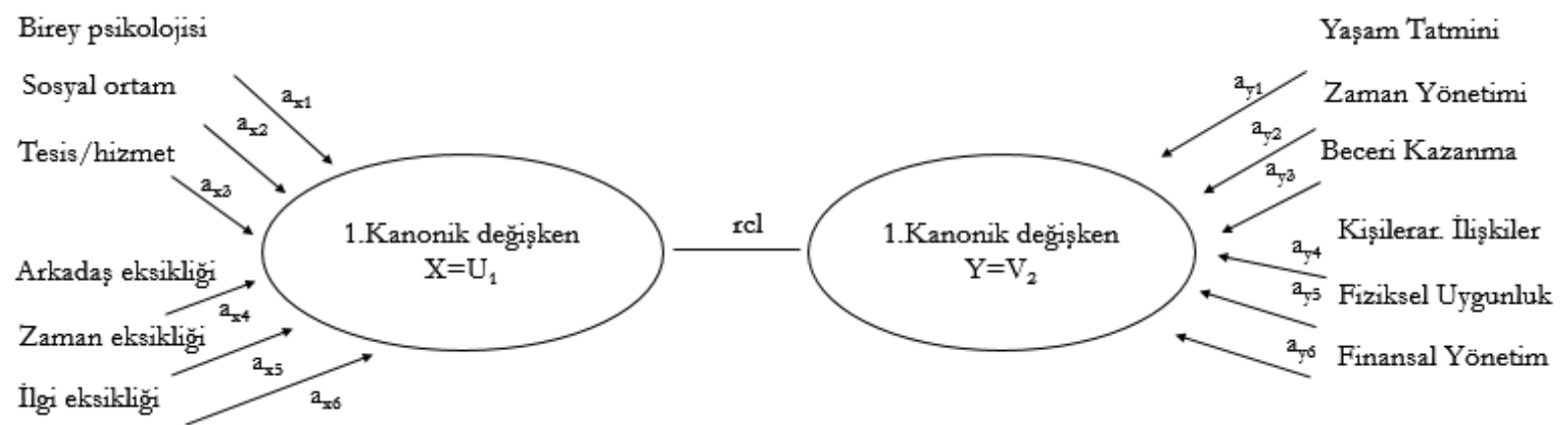

Şekil 1. Kanonik korelasyona ait analitik yaklaşım

ax1, ax2 ... = X değişkeni için kanonik yükler

ay1, ay2 ... = Y değişkeni için kanonik yükler

rc1 = Birinci kanonik değişkenler arasındaki korelâsyon 
Kanonik fonksiyonu oluşturan değişkenlerden ilki birinci değiş̧en kümesine aitken diğeri ikinci değişken kümesine aittir. KKA'da kurulan kanonik fonksiyon sayısı, az sayıdaki değişken kümesinin sayısına eşittir. Bu çalışmada değişkenlerin sayısı eşittir ve kurulan kanonik fonksiyon sayısı altıdır.

\section{GEREÇ VE YÖNTEMLER}

\section{Araştırmanın Modeli}

$\mathrm{Bu}$ araştırma nicel araştırma yöntemine dayalı olarak ilişkisel model bağlamında yapılmıştır. İlişkisel araştırmalarda iki veya ikiden daha fazla değiş̧ken arasındaki ilişki incelenir (Büyüköztürk, Çakmak, Akgün, Karadeniz \& Demirel, 2014).

\section{Araştırmanın Evren ve Örneklemi}

Araştırmanın evrenini Akdeniz üniversitesinde okuyan öğrenciler oluşturmaktayken araştırmanın örneklemi ise 190 (Ortyas $=20.83 \pm 1.85)$ kadın ve 196 (Ortyas $=21.23 \pm 1.89)$ erkek toplam 386 (Ortyas $=21.02 \pm 1.88)$ üniversite öğrencisinden oluşmaktadır. Araştırmanın örneklem seçiminde tesadüfi olmayan örnekleme yöntemleri içinden kolayda örnekleme yöntemi tercih edilmiştir.

\section{Veri Toplama Araçları}

Veri toplama aracı olarak boş zaman engelleri ölçeği ve serbest zaman kolaylaştırıcıları ölçeği kullanılmıştır.

\section{Boş Zaman Engelleri Ölçeği}

Bu çalışmada 1997 yılında Alexandris ve Carroll tarafından geliştirilen, Karaküçük ve Gürbüz (2007) tarafından Türkçeye uyarlanan ve (2012)'de Gürbüz Öncü ve Emir tarafından Türkçe'ye kısa formu adapte edilen "Boş Zaman Engelleri Ölçeği-18" veri toplama aracı olarak kullanılmıştır. Rekreasyonel faaliyetlere katılımı engelleyen faktörleri değerlendiren özgün ölçek 27 madde ve 6 alt boyuttan oluşan 4'lü Likert tipi dereceleme ölçeğidir. Bu araştırmada ise 18 madde 6 alt boyuttan oluşan boş zaman engelleri ölçeğinin kısa formu kullanılmıştır. Her bir soru için 1: “Kesinlikle Önemsiz”, 2: “Önemsiz”, 3: “Önemli”, 4: “Çok Önemli”, seçenekleri sunulmuş ve araştırma grubundan görüşlerine en uygun seçeneği işaretlemeleri istenmiştir. Boş Zaman 
Engelleri Ölçeği-18'in alt boyutları ise; (a) Birey Psikolojisi (3 madde), (b) Bilgi eksikliği (3 madde), (c) Tesis (3 madde), (d) Arkadaş eksikliği (3 madde), (e) Zaman (3madde) ve (f) ilgi eksikliği (3 madde) oluşturmaktadır. Ölçek alt faktörleri için Cronbach Alfa güvenirlik katsayıları .65 ile .86 arasında değişirken ölçeğin tümü için .85 olarak hesaplanmıştır (Gürbüz ve ark., 2012). $\mathrm{Bu}$ çalışma için ölçeğin genelinde ilişkin iç tutarlılık katsayısı .76 iken, ölçeğin alt faktörlerine ilişkin iç tutarlılık katsayıları sırası ile $.60, .82, .74, .80, .60$ ve .70 olarak saptanmıştır.

\section{Serbest Zaman Engelleri ile Baş etme Stratejileri Ölçeği}

Hubbard ve Mannell tarafindan (2001) yllında geliştirilen daha sonra Elkins ve Powers (2004) tarafından rekreasyonel amaçlı kampüs sporlarına uyarlanan ve 2005'te yine Beggs, Elkins ve Powers tarafından geçerliği yapılan bu ölçek Türkiye'deki üniversite öğrencilerine yönelik olarak Yerlisu Lapa (2014) tarafindan "Serbest Zaman Engelleri ile Baş Etme Stratejileri Ölçeği” olarak adapte edilmiştir. Ölçeğin orijinali 31 maddeden altı alt boyuttan oluşmaktadır. $\mathrm{Bu}$ alt boyutlar zaman yönetimi stratejileri, beceri kazanma stratejileri, kişilerarası ilişkiler, içsel onaylama stratejileri, fiziksel uygunluk stratejileri ve finansal yönetimden oluşmaktadır. Türkçe geçerlik ve güvenirliği yapılmış olan ölçek ise 27 madde altı alt boyuttan oluşmaktadır. Ölçek 1 ile 5 puan arasında değerlendirilmekte 1 "Asla", 5 ise "Çok sık" olarak ifade edilmektedir. Cronbach Alfa güvenirlik katsayısı 6 alt boyut için .70 ile .77 arasında değişirken, ölçeğin geneline ilişkin ise .81 olarak bulunmuştur (Yerlisu Lapa, 2014). Bu çalışma için ise alt boyutlara ilişkin iç tutarlılık katsayıları .60 ile .77 arasında değişirken, ölçeğin geneline ilişkin .73 olarak saptanmıştır.

\section{Verilerin Toplanması}

Araştırmaya ilişkin veriler geçerlik ve güvenirliği kanıtlanmış ölçme araçları ile toplanmış olup 2018 yllının ilk çeyreğinde, Antalya Akdeniz Üniversite'sinde okuyan öğrencilere uygulanmıştır. Ölçeğin doldurulması için öğrencilere 15 dakikalık süre tanınmış, ölçekler tamamlandıktan sonra veriler araştırmacı tarafından paket programı ile değerlendirilmiştir. Araştırmacı üniversite kampüsündeki belli noktalara ölçekleri koymuş (kantinler, yüzme havuzu, tenis kortları vs.) ve yetkililere araştırmaya ilişkin bilgi vererek öğrencilerin gönüllülük esası dahilinde katılımlarını teşvik etmeleri istenmiştir 


\section{Verilerin Analizi}

Araştırma bulguları dahilinde elde edilen verilere ilişkin betimsel istatistikler paket programında değerlendirilmiştir. Yapılan analizde öğrencilerin demografik bilgileri, aritmetik ortalama $(O r t)$, yüzde $(\%)$ ve standart sapma $(S s)$ olarak verilmiştir. Bununla birlikte her biri iki veya daha fazla değişkenden oluşan iki değişken arasındaki ilişkiyi değerlendiren kanonik korelasyon analizi (KKA) yapmak için temel varsayımlar değerlendirilmiştir. Buna göre KKA'ya ilişkin istatistiksel ve pratik sonuçlar oluşabilmesi içinde bu temel varsayımlar değerlendirilmelidir. KKA'nın temel varsayımları; normallik, doğrusallık, eş varyanslılık ve çoklu bağlantı problemlerinin olup olmadığı test edilmiştir (Temurtaş, 2016). Bu varsayımlardan normallik dağılımını test etmek için veriler çoklu bakış açısı dahilinde değerlendirilmiş; mod, medyan ve aritmetik ortalama değerlerine bakılmış, histogram grafiği incelenmiş, KolmogorovSmirnov testi yapılmış ve çarpıklık ile basıklık değerleri incelenmiştir. Buna göre mod, medyan, aritmetik ortalama değerleri birbirine yakın olup, histogram grafikleri normal dağılım özellikleri göstermekte, bununla birlikte çarpıklık ve basıklık değerleri -1 ile +1 arasında yer almaktadır. Kolmogorov-Smirnov testi hariç diğer tüm testler, verilerin normal dağıldığına ilişkin ipuçları vermektedir. Ancak Kolmogorov-Smirnov testi sonuçları anlamlı görünmektedir $(p=.000)$. Bu durum ise Kolmogorov-Smirnov testinin örneklem büyüklüğünün artması ile beklenen ve gözlenen dağılımlardaki küçük farkların anlamlı çıkma eğiliminin artması ile sonuçlanabileceği şeklinde açıklanabilir (Çokluk, Şekercioğlu ve Büyüköztürk, 2010).

\section{BULGULAR}

Çalışmanın kanonik korelasyon sonuçları değerlendirildiğinde öncelikli olarak kanonik fonksiyonların anlamlılı̆̆ı değerlendirilmiştir. Bu amaçla sonuçların anlamlı olup olmadığını saptamak amacıyla çok değişkenli anlamlılık testi sonuçlarına bakılmıştır. Pillais, Hotellings, Wilks ve Roys testlerinin F değerleri kanonik fonksiyonların anlamlılığı hakkında bilgi vermekle birlikte araştırmalarda en fazla kullanılan ve uygulanabilirliği daha fazla olan Wilks'in $\lambda$ sonuçları ele alınmıştır. Sonuçlar Tablo 1'de verilmiştir. 
Tablo 1. Modele iliş̧kin anlamlılık testi ve özet bilgiler

\begin{tabular}{lcc}
\hline Kanonik R & \multicolumn{2}{c}{.433 } \\
Serbestlik derecesi & \multicolumn{2}{c}{193.26} \\
Ki-kare değeri & .000 \\
p değeri & Serbest Zaman Engelleri & Engelleri ile Baş etme \\
Değişken Seti & 100.00 & 100.00 \\
Elde edilen varyans & 9.70 & 10.41 \\
Açıklanan varyans (Redundancy) & 6 & 6 \\
Değiş̧ken sayısı & $\mathrm{X}_{1}, \mathrm{X}_{2}, \mathrm{X}_{3}, \mathrm{X}_{4}, \mathrm{X}_{5}, \mathrm{X}_{6}$ & $\mathrm{Y}_{1}, \mathrm{Y}_{2}, \mathrm{Y}_{3}, \mathrm{Y}_{4}, \mathrm{Y}_{5}, \mathrm{Y}_{6}$ \\
Değişkenler & & \\
\hline
\end{tabular}

Tablo 1 incelendiğinde bağımlı ve bağımsız değişkene ilişkin sayılar ve bu değişkenler ile kurulan modele ilişkin istatistik değerler görülmektedir. Buna göre 6 bağımsız 6 bağımlı değişken ile kurulan kanonik fonksiyon anlamlıdır. Redundancy değeri incelendiğinde serbest zaman engelleri kümesinin varyansının \%9.70’i serbest zaman engelleri ile baş etme stratejileri tarafından açıklanırken, serbest zaman engelleri ile baş etme stratejileri kümesinin \%10.41'inin serbest zaman engelleri kanonik değişkeni tarafından açıklandığı görülmektedir.

Tablo 2. Modele ilişkin öz değerler ve kanonik korelasyon değerleri

\begin{tabular}{lllllll}
\hline Kök No. & $\begin{array}{l}\text { Kanonik } \\
\text { korelasyon }\end{array}$ & Kanonik R2 & Ki-kare & df & $\mathrm{p}$ & $\lambda$ \\
\hline 1 & .433 & .188 & 193.25 & 36 & .000 & .600 \\
2 & .391 & .153 & 114.33 & 25 & .000 & .739 \\
3 & .311 & .097 & 51.19 & 16 & .000 & .873 \\
4 & .146 & .021 & 12.46 & 9 & .188 & .967 \\
5 & .105 & .011 & 4.26 & 4 & .371 & .988 \\
6 & .009 & .000 & .03 & 1 & .848 & .999 \\
\hline
\end{tabular}

Tablo 2'de ise oluşturulan kanonik fonksiyonlara (Root1, Root2, Root3, Root4, Root5 ve Root6) ilişkin bilgiler yer almaktadır. Sonuçlar değerlendirildiğinde ilk üç kanonik fonksiyonun anlamlı olduğu görülmektedir. İlk kanonik fonksiyon değerlendirildiğinde; serbest zaman engelleri ile serbest zaman engelleri ile baş etme stratejilerinin \%18.82'lik ortak bir varyansa sahip olduğu saptanmıştır. anlamlı olduğu saptanan ikinci kanonik fonksiyona ilişkin ortak varyans \%15.36 iken, üçüncü kanonik fonksiyona ilişkin ortak varyansın \%9.72 olduğu görülmektedir. Ayrıca çalışmada altı kanonik değişken çifti olması nedeniyle altı kanonik fonksiyon elde edilmiş, bu altı kanonik fonksiyonun toplam varyansa olan katkısı ve açıladığı varyansı ise Tablo 3'de verilmiş̧ir. 
Tablo 3. Bağımsız değişken setindeki ilişkiler

\begin{tabular}{ccccccc}
\hline & $\mathrm{X}_{1}$ & $\mathrm{X}_{2}$ & $\mathrm{X}_{3}$ & $\mathrm{X}_{4}$ & $\mathrm{X}_{5}$ & $\mathrm{X}_{6}$ \\
\hline $\mathrm{X}_{1}$ & 1.00 & & & & & \\
$\mathrm{X}_{2}$ & .07 & 1.00 & & & & \\
$\mathrm{X}_{3}$ & .04 & .33 & 1.00 & & & \\
$\mathrm{X}_{4}$ & -.03 & .07 & .03 & 1.00 & 1.00 & \\
$\mathrm{X}_{5}$ & .13 & .31 & .26 & .07 & .17 & 1.00 \\
$\mathrm{X}_{6}$ & .12 & .16 & -.03 & .00 & .00 \\
\hline
\end{tabular}

Tablo 3’te bağımsız (X) değişkenin doğrusal ilişkileri görülmekte ve bu doğrusal ilişkiye ait korelasyon katsayılarının -.03 ile .33 arasında değiştiği belirlenmiştir. Serbest zaman engelleri arasındaki ilişkiler incelendiğinde değişken seti arasındaki en yüksek ilişkinin $\mathrm{X}_{2}$ ile $\mathrm{X}_{3}$ arasında yani tesis/hizmet ve ulaşım ile sosyal ortam ve bilgi eksikliği arasında olduğu görülmektedir $(r=$ .33). En düşük ilişki ise $X_{4}$ ve $X_{6}$ arasındadır $(r=.00)$. Buna göre $X_{4}$ ve $X_{6}$ arasında yani arkadaş eksikliği ve ilgi eksikliği arasında bir ilişki bulunmamaktadır. Diğer değişken setleri arasındaki ilişkilere bakıldığında da düşük düzeyde ilişkiler olduğu görülmektedir.

Tablo 4. Bağımlı değişken setindeki ilişkiler

\begin{tabular}{ccccccc}
\hline & $\mathrm{Y} 1$ & $\mathrm{Y} 2$ & $\mathrm{Y} 3$ & $\mathrm{Y} 4$ & $\mathrm{Y} 5$ & $\mathrm{Y} 6$ \\
\hline $\mathrm{Y} 1$ & 1.00 & & & & & \\
$\mathrm{Y} 2$ & .22 & 1.00 & & & & \\
$\mathrm{Y} 3$ & .14 & -.00 & 1.00 & & & \\
$\mathrm{Y} 4$ & .20 & .11 & .17 & 1.00 & & \\
$\mathrm{Y} 5$ & .18 & .31 & .02 & .22 & 1.00 & \\
Y6 & .19 & .24 & .09 & .16 & .30 & 1.00 \\
\hline
\end{tabular}

Tablo 4 incelendiğinde bağımlı (Y) değişkene ilişkin veri setindeki doğrusal ilişkiler görünmektedir. Buna göre bağımlı değişkene ilişkin korelasyon katsayılarının .00 ile .31 arasında değişkenlik gösterdiği görülmektedir. Buna göre bağımlı değişken veri setindeki en yüksek ilişki $\mathrm{Y}_{5}$ ile $\mathrm{Y}_{2}$ arasindadir $(r=.31)$. Bu durum fiziksel uygunluk ve beceri kazanma stratejileri arasında orta şiddette doğrusal bir ilişki olduğunu ortaya koymaktadır. $\mathrm{Y}_{2}$ ile $\mathrm{Y}_{3}$ arasında yani kişilerarası ilişskiler ile beceri kazanma stratejileri arasında herhangi bir ilişki yoktur $(r=.00)$. Genel anlamda bağımlı değişkene ilişkin veri seti değerlendirildiğinde genellikle düşük düzeyde ilişkiler olduğu görülmektedir. 
Tablo 5. $X$ ve y değişken setleri arasındaki ilişkiler

\begin{tabular}{ccccccc}
\hline & $\begin{array}{c}\text { Y1:Zaman } \\
\text { yönetimi } \\
\text { stratejileri }\end{array}$ & $\begin{array}{c}\text { Y2:Beceri } \\
\text { kazanma } \\
\text { stratejileri }\end{array}$ & $\begin{array}{c}\text { Y3:Kişileraras1 } \\
\text { ilişkiler }\end{array}$ & $\begin{array}{c}\text { Y4:İçsel } \\
\text { doğrulama } \\
\text { stratejileri }\end{array}$ & $\begin{array}{c}\text { Y5:Fiziksel } \\
\text { uygunluk } \\
\text { stratejileri }\end{array}$ & $\begin{array}{c}\text { Y6:Finans } \\
\text { yönetim }\end{array}$ \\
\hline $\begin{array}{c}\text { X1: Birey } \\
\text { psikolojisi }\end{array}$ & .089833 & .006794 & -.027566 & .258731 & .081621 & .046652 \\
$\begin{array}{c}\text { X2: Sosyal } \\
\text { ortam }\end{array}$ & .228956 & .199982 & -.025063 & .142474 & .207139 & .125118 \\
$\begin{array}{c}\text { X3: Tesis/ } \\
\text { Hizmet }\end{array}$ & .162462 & .232964 & .030210 & .065938 & .248425 & .226319 \\
$\begin{array}{c}\text { X4: Arkadaş } \\
\text { eksikliği }\end{array}$ & .111728 & -.029644 & .370467 & .105699 & -.032376 & .037103 \\
$\begin{array}{c}\text { X5: Zaman } \\
\text { eksikliği }\end{array}$ & .153941 & .230331 & .098697 & .076433 & .232025 & .221369 \\
$\begin{array}{c}\text { X6: İlgi } \\
\text { eksikliği }\end{array}$ & .133217 & -.054350 & .023158 & .081542 & .095860 & .033649 \\
\hline
\end{tabular}

Tablo 5 incelendiğinde ise bağımsız (x) ve bağımlı (y) setleri arasındaki ilişkiler görülmektedir. Buna göre $\mathrm{X}$ ve $\mathrm{Y}$ değişken setleri arasındaki ilişkilerin .00 ile .37 arasında değiştiği, en yüksek ilişkinin ise $\mathrm{X}_{4}$ : arkadaş eksikliği ile $\mathrm{Y}_{3}$ : kişilerarası ilişkiler arasında olduğu saptanmıştır $(r=.37 ; p=.000)$. Bununla birlikte en yüksek ikinci ilişki $\mathrm{X}_{1}$ : birey psikolojisi ile $\mathrm{Y}_{4}$ : içsel doğrulama stratejileri $(r=.25 ; p=.000)$ ve $\mathrm{X}_{3}$ : tesis/hizmet ile $\mathrm{Y}_{5}$ :Fiziksel uygunluk stratejileri arasındadır $(r=.24 ; p=.000)$. Ancak tablo 5 bütüncül bir şekilde değerlendirildiğinde $\mathrm{X}_{4}$ : arkadaş eksikliği ile $\mathrm{Y}_{3}$ : kişilerarası ilişkiler dışında diğer tüm değişkenler arasındaki ilişkilerin düşük düzeyde olduğu söylenebilir. $X$ ve $Y$ değişkenine ilişkin daha detaylı ilişki saçılım grafiğinde verilmiştir (Şekil 2). 


\section{Correlations (Engeller ve Basetme Stratejileri.sta 12v³86c)}

\begin{tabular}{|c|c|c|c|c|c|c|c|c|c|c|c|}
\hline & 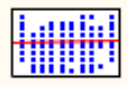 & 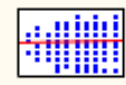 & 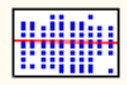 & 洋留: & 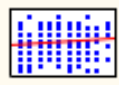 & 要 & 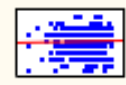 & : & 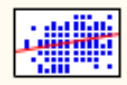 & 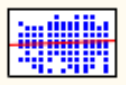 & 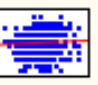 \\
\hline 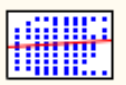 & andhol & 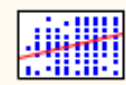 & 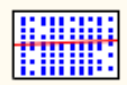 & 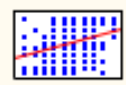 & 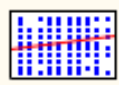 & & & & 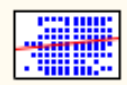 & 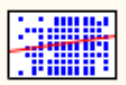 & \\
\hline 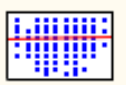 & 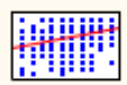 & andho & 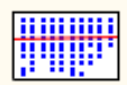 & 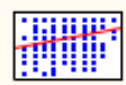 & 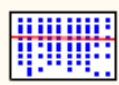 & 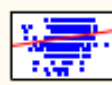 & & & 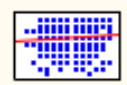 & 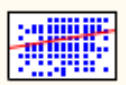 & \\
\hline 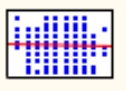 & 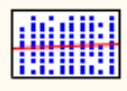 & 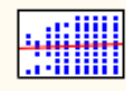 & andm & 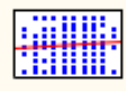 & 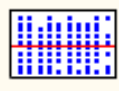 & & & & & \begin{tabular}{|l|} 
\\
3
\end{tabular} & \\
\hline 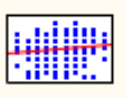 & 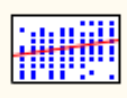 & 胃曲宷: & 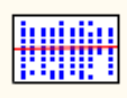 & anllh. & 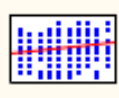 & & & & 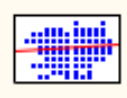 & 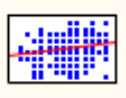 & \\
\hline 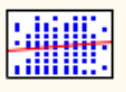 & 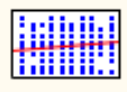 & 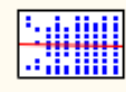 & 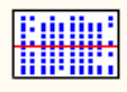 & 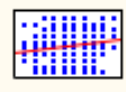 & WNilhth & & & 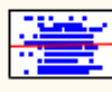 & 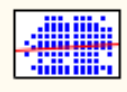 & 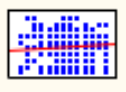 & \\
\hline :inlleti: & 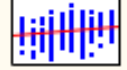 & 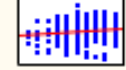 & 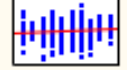 & i州!!!ị! & 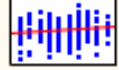 & & & & & & \\
\hline 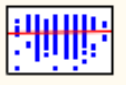 & 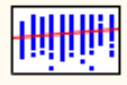 & 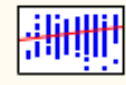 & 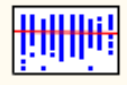 & :in+llll: & 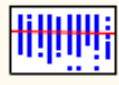 & & & & & & \\
\hline :泮州: & 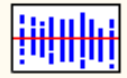 & 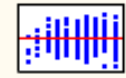 & 进州安 & ii iill|ili & 米i: & & & & & & \\
\hline r!lllll!! & Hịl曲. & 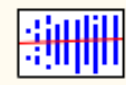 & Hill听 & بi州州 & 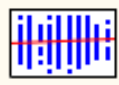 & & & & & 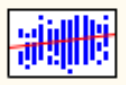 & \\
\hline 浯州曲 & 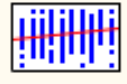 & 玄: & 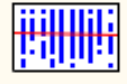 & 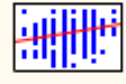 & 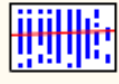 & & & & 辛: & & \\
\hline ;itlllt!̣ & iiiinl曲 & 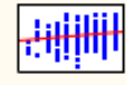 & ilin州i: & 萑ịlllt: & 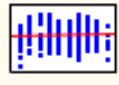 & & & & & in & \\
\hline
\end{tabular}

Şekil 2. x ve y değişken setleri için değişkenlere ait saçılım grafiği

Tablo 6. Orijinal değişkenler ile kanonik değişkenler arasındaki ilişkiler

\begin{tabular}{|c|c|c|c|c|c|c|}
\hline & $\mathbf{U}_{1}$ & $\mathbf{U}_{2}$ & $\mathbf{U}_{\mathbf{3}}$ & $\mathbf{U}_{4}$ & $\mathbf{U}_{5}$ & $\mathbf{U}_{6}$ \\
\hline $\mathrm{X}_{1}$ : Birey psikolojisi & 2449 & -.0524 & -.7821 & -.4124 & .3887 & -.0651 \\
\hline $\mathrm{X}_{2}:$ Sosyal ortam & 6717 & -.1649 & -.2647 & .1325 & -.6579 & -.0329 \\
\hline $\mathrm{X}_{3}$ : Tesis/hizmet ulaşım & .7517 & -.0824 & .2044 & .0242 & .1775 & .5950 \\
\hline $\mathrm{X}_{4}$ : Arkadaş eksikliği & .1330 & .9607 & -.0693 & -.0360 & -.2008 & .1132 \\
\hline $\mathrm{X}_{5}:$ Zaman eksikliği & .7351 & .0910 & .2404 & -.1168 & .1578 & -.5957 \\
\hline \multirow[t]{2}{*}{$\mathrm{X}_{6}$ : İlgi eksikliği } & .1999 & .0727 & -.3787 & .8127 & .2645 & -.2842 \\
\hline & $\mathbf{V}_{1}$ & $\mathbf{V}_{2}$ & $\mathbf{V}_{3}$ & $\mathbf{V}_{4}$ & $V_{5}$ & $V_{6}$ \\
\hline $\mathrm{Y}_{1}$ : Zaman yönetimi st. & .5925 & .1669 & -.3152 & .4515 & -.4671 & .3154 \\
\hline $\mathrm{Y}_{2}:$ Beceri stratejileri & .6635 & -.1925 & .3225 & -.4747 & -.4323 & -.0791 \\
\hline $\mathrm{Y}_{3}$ : Kişilerarası ilişkiler & .1676 & .9653 & .1187 & -.0473 & .0117 & -.1534 \\
\hline $\mathrm{Y}_{4}$ : İçsel doğrulama st. & .3707 & .1810 & -.7814 & -.4393 & .1427 & -.0750 \\
\hline $\mathrm{Y}_{5}$ : Fiziksel uygunluk st. & .7329 & -.1754 & -.0006 & .2248 & .3224 & -.5267 \\
\hline $\mathrm{Y}_{6}:$ Finansal yönetim & .6222 & .0400 & .1880 & -.1031 & .5197 & .5426 \\
\hline
\end{tabular}

$A$ ve $B$ vektörlere ait ağırlık değerleri olmak üzere $U$ ve $V$ doğrusal bileşenleri için elde edilen kanonik katsayılar Tablo 6'da gösterilmiştir. Tablo 6 incelendiğinde istatistiksel olarak 
anlamlı bulunan $\mathbf{U}_{\mathbf{1}}-\mathbf{V}_{\mathbf{1}}, \mathbf{U}_{\mathbf{2}}-\mathbf{V}_{\mathbf{2}}, \mathbf{U}_{\mathbf{3}}-\mathbf{V}_{\mathbf{3}}$ kanonik değişken çiftleri arasındaki saçılım diyagramı ise Şekil 3'de verilmiştir.
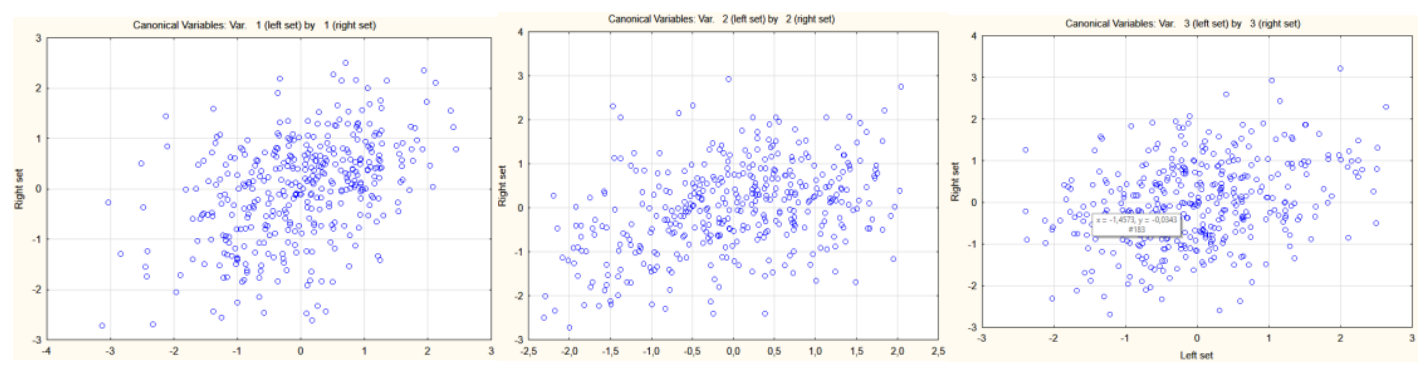

Şekil 3. $U_{1}-V_{1}, U_{2}-V_{2}, U_{3}-V_{3}$ kanonik değişken çifti için saçılım grafiği

Şekilde görüldüğü üzere aralarında anlamlı bir ilişki bulunan $U_{1}-V_{1}, U_{2}-V_{2}, U_{3}-V_{3}$ kanonik değişken çifti arasında doğrusal bir ilişki olduğu belirlenmiştir. Buna göre elde edilen sonuçlar matematiksel olarak modellendiğinde Tablo 7'nin birinci sütunundaki kanonik katsayılara göre elde edilen eşitlik aşağıda gösterilmiştir;

$\mathrm{U}_{1}=.24$ birey psikolojisi +.67 sosyal ortam +.75 tesis/hizmet/ulaşım +.13 arkadaş eksikliği + .73 zaman eksikliği +.19 ilgi eksikliği

$\mathrm{V}_{1}=.59$ zaman yönetimi stratejisi +.66 beceri stratejileri +.16 kişilerarası ilişkiler +.37 içsel doğrulama stratejileri +.73 fiziksel uygunluk stratejileri +.62 finansal yönetim

Serbest zaman engelleri olarak tanımlanan $U_{1}$ kanonik değişkenine en önemli katkıların .75 tesis/hizmet/ulaşım, .73 zaman eksikliği ve .67 sosyal ortamın sağladığı görülürken diğer değişkenlerin sıra ise katkıları .24 ile birey psikolojisi, .19 ile ilgi eksikliği ve .13 ile arkadaş eksikliğidir.

Serbest zaman engelleri ile baş etme stratejileri olarak tanımlanan $\mathrm{V}_{1}$ kanonik değişkenine en önemli katkının ise .73 ile fiziksel uygunluk stratejilerinin olduğu görülmektedir. $\mathrm{V}_{1}$ kanonik değişkenine katkı sağlayan diğer değişkenler ise sırası ile .66 beceri stratejileri, .62 finansal yönetim, .59 zaman yönetimi stratejileri, .37 içsel doğrulama stratejileri ve .16 ile kişilerarası ilişkilerdir. 


\section{TARTIŞMA VE SONUÇ}

Serbest zaman engelleri ve baş etme stratejileri arasındaki ilişki anlamlı üç kanonik fonksiyon ile açıklanmaktadır. Oluşturulan bazı kanonik değişkenler arasındaki ilişkiler çok düşük olabildiği gibi istatistiksel olarak da anlamlı olmayabilir. Bu nedenle her bir kanonik fonksiyonun kanonik model ile anlamlılığının da değerlendirilmesi önemlidir. $\mathrm{Bu}$ durumda kanonik fonksiyonların hangilerinin anlamlı olduğuna ilişkin karar verebilmek için; öz değerler ve bunlara ilişkin yüzdelik değerlerin hesaplanması gerekir. Bu bilgi dahilinde ilk üç kanonik fonksiyonun anlamlı olduğu görülmektedir. İki değişken kümesine ilişkin ortak varyansın ilk kanonik fonksiyon için \%18.8, ikinci kanonik fonksiyon için \%15.3 ve üçüncü kanonik fonksiyon için \%1 oranında açıklandığı görülmektedir. Bununla birlikte serbest zaman engelleri, baş etme stratejilerini \%10.41 oranında açıklarken serbest zaman engelleri ile baş etme stratejileri serbest zaman engellerinin \%9.7'sini açıklamaktadır. Bir başka deyişle serbest zaman engelleri ve bu engeller ile baş etme stratejileri birbiri ile pozitif ilişkilidir. Uluslararası alanyazın incelendiğinde serbest zaman engelleri ile baş etme stratejilerinin teorik alt yapısını ortaya koyan Hubbard ve Mannell (2001); serbest zaman engelleriyle baş etme stratejilerini dört teorik temel ile açıklamaya çalışmışlardır. Bunlardan ilki engellerin etkisini hafifletme modelidir. Bu modele göre Hubbard ve Mannell (2001) herhangi bir aktiviteye katılım sağlamada engel oluşturan unsurları sınırlayan en önemli etkinin engellerle baş etme stratejileri olduğunu ortaya koymaktadır. Jackson (2005)'ın engeller teorisi de Hubbard ve Mannell' in yaptığı çalışmayı destekler nitelikte bulgular ortaya koymuştur. Jackson (2005)'ın çalışmasına göre; serbest zaman engelleri ile baş etme stratejileri arasında pozitif ilişki bulunmaktadır. Bu durum şu şekilde açıklanabilir; bir bireyin herhangi bir serbest zaman aktivitesine katılım sağlamasında karşılaştığı engeller varsa, kişi bu engelleri aşmaya yönelik baş etme stratejileri geliştirmektedir. Başka bir deyişle, engel varsa baş etme stratejisi vardır (Chen, Lou ve Ma, 2018; Hubbard ve Mannell 2001; Loucks-Atkinson ve Mannell, 2007; White, 2008). Bu bağlamda alanyazında yapılan çalışmaların sonuçları ile bu araştırma sonuçları paralellik göstermekte, serbest zaman engelleri arttıkça bu engeller ile baş etme stratejileri artmaktadir.

Yapılan çalışmada tartışılması gereken bir diğer husu, iki değişken seti arasındaki ilişkilerdir. Bireyler, serbest zamana katılımlarına ilişkin hangi engellerle karşılaşmakta ve bu engelleri aşmaya yönelik ne tür baş etme stratejileri geliştirmektedir? Çalışma sonuçları dahilinde, arkadaş eksikliği nedeniyle herhangi bir serbest zaman aktivitesine katılamayan bireylerin bu 
sorunu aşmak için kişilerarası ilişkileri güçlendirmeye çalıştıkları yorumu yapılabilir. Serbest zaman engelleri ve bu engeller ile baş etme stratejileri üzerinde çalışan araştırmacılar, yaptıkları çalışmalarda bu ilişkileri ortaya koyan bulgular elde etmişlerdir. Örneğin, Jackson ve Rucks (1995) yapmış oldukları çalışmada herhangi bir etkinliğe katılmak için arkadaş eksikliği yaşayan ve çekingen olan bireylerin kendisi ile birlikte etkinliğe katılacak kişileri davet ettikleri, böylelikle serbest zaman aktivitelerinin sıkıcı yanlarından da kurtulduklarını ifade ederek kişilerarası engelleri aşmaya çalıştıklarını ifade etmektedir. Yine engeller ve engellerle baş etme stratejileri üzerinde çalışan bir başka araştırmacı ikilisi de Hubbard ve Mannell'dir. Hubbard ve Mannell (2001) yapmış oldukları çalışmada da, arkadaş eksikliği yaşayan kişiler bu durumu serbest zaman aktivitelerine katılmak için bir engel olarak görmekte, herhangi bir etkinliğe katılmak için arkadaş bulamamakta ya da mevcut arkadaşlarının etkinliklere katılmak için benzer ilgi alanlarına sahip olmadığını dile getirmektedirler. Arkadaş eksikliği engeli ile karşılaşan bu bireylerin, çözüm yolu olarak kendi ilgi alanlarına sahip olan bireyler ile bir araya gelmeye çalıştıkları, onlarla aktiviteye katılacak bireyler aramaları ve aynı cinsiyetten olan kişileri tercih ettikleri ve böylelikle bu engelleri aşmaya çalıştıkları ifade edilmiştir. Uluslararası alanyazında yapılan nitel çalışmaların bulguları da oldukça önemli olup, bireylerin karşılaştıkları engellere karşı nasıl baş etme stratejileri geliştirdikleri nedensel bir şekilde ele alınmıştır. Yapılan çalışmaların çoğunlukla dezavantajlı olarak kabul edilen, engelli bireyler ve kadınlar üzerine yoğunlaştığı göze çarpmaktadır. $\mathrm{Bu}$ çalışmalardan biri Koca ve ark. (2009) ait olup, Türk toplumundaki kadınları sosyal sınıf bağlamında ele alarak engelleri ve bu engellerle baş etme stratejilerini incelemişlerdir. Çalışma sonuçları, kişilerarası engellerden biri olan aileye ilişkin sorumluluklar, kadınların serbest zaman katılımını etkilemektedir. Bu engele karşı kadınların geliştirdiği baş etme stratejileri ise; aile bireyleri ve sosyal çevrelerinden aldıkları onaydır. Bir başka deyişle kişilerarası engellerle karşılaşan kadınlar yine kişilerarası ilişkileri geliştirerek bu engeller ile baş edebilmektedir. $\mathrm{Bu}$ sonuçlar yine araştırmamızın sonuçları ile paralellik göstermektedir.

Serbest zaman engelleri ve bireylerin bu engeller ile nasıl baş ettiklerini araştıran bir başka çalışmanın sonuçları da dikkate değerdir. Elkins (2004) kampüs rekreasyonuna ilişkin serbest zaman engelleri ile baş etme stratejilerine yönelik kuramsal bir çalışma yapmıştır. Elkins (2004)'in yapmış olduğu çalışmanın sonuçları kişilerarası engellerin büyük ölçüde finansal yönetim stratejisi ve serbest zaman tercihlerini değiştirme stratejisi ile ilişkili olduğunu ortaya koymuştur. Daha detaylı bir şekilde ifade edilecek olunursa, kişiler arası engellerle karşılaşan bireyler ya aktiviteye 
katılmak için uygun bir arkadaş bulamadığı için serbest zaman niyetini değiştirmekte ya da bu etkinliğe katılmak için aynı finansal düzeye sahip arkadaşlar edinmeyi uygun görmektedir. Elkins (2004)'e göre kişiler arası engeller ve finansal destek arasındaki ilişki belirsizdir. Bu nedenle bireyler, finansal destek aracılığı ile başka arkadaş grupları bulmayı hedeflenmiş olabilir. Elkins (2004)'in yorumundan yola çıkarak; kişilerarası engellere sahip olan bireylerin yine kişiler arası ilişkileri geliştirmek için stratejiler aradığı veya diğer stratejileri kişilerarası ilişkileri geliştirmek için bir araç olarak kullandığı yorumunu yapabiliriz.

Araştırmada önemli bulgulardan bir diğeri ise; bireylerin psikolojik engeller ile karşılaştıkları zaman bu engelleri aşmaya yönelik içsel doğrulama stratejileri geliştirmeleridir. Araştırmanın bulgusu yine kuramsal çalışmalar ile birebir paralellik göstermekte; herhangi bir serbest zaman aktivitesine katılmak için motivasyon bulamayan ya da o etkinliğe karşı ilgi duymayan bireylerin bu engelleri aşmak için kendine uygun aktiviteler belirlediği, rekabet etmekten kaçınabileceği aktiviteleri tercih ettiği ya da kendini iyi olarak gördüğü aktivitelere katılmayı tercih ettiği görülmektedir (Elkins, 2004; Beggs ve ark., 2005).

Alanyazın incelendiğinde; bireylerin psikolojik engelleri ve bu engeller ile nasıl baş ettiklerine ilişkin çalışmalar sınırlı olmasına karşın, psikolojik engelleri kapsayan motivasyon ve motivasyonun baş etme stratejileri üzerindeki etkilerini ele alan çalışmalar azımsanmayacak kadar fazladır. $\mathrm{Bu}$ çalışmalar incelendiğinde; serbest zaman katılımında motivasyonun, baş etme stratejilerini arttırdığı diğer bir deyişle motivasyon ve baş etme stratejilerinin pozitif ilişkili olduğu görülmektedir. Hubbard ve Mannell (2001)'in serbest zaman katılımı etkileyen faktörler üzerine yapmış olduğu bir çalışmada; serbest zaman katılımında aracı değişken görevini baş etme stratejilerinin üstlendiği, baş etme stratejilerini ise serbest zaman motivasyonunun etkilediği ortaya konulmuştur. Bu sonuçlar ile benzerlik gösteren başka çalışmalarda bulunmakta ve bu çalışmalar, serbest zaman engelleri, baş etme stratejileri ve motivasyonun serbest zaman katılımı üzerindeki etkilerini incelemektedir. Yapılan çalışmalarda motivasyonun, baş etme stratejileri üzerinde pozitif etkisi olduğu ortaya konulmuştur (White, 2008; Son, Mowen ve Kerstetter, 2008b).

Yapılan çalışmada iki değişken seti arasındaki ilişkilerle birlikte tartışılması gereken bir diğer bulgu ise kanonik fonksiyonlara en fazla katkı yapan değişkenler arasındaki ilişkilerdir. Serbest zaman engelleri değişken kümesinin (U1) kanonik değişkene yaptığı en önemli katkı .75 tesis/hizmet/ulaşım iken, serbest zaman engelleri ile baş etme stratejilerinin (V1) kanonik 
değişkenine yaptığı katkı ise .73 ile fiziksel uygunluk stratejileridir. Bu sonuçlar dahilinde serbest zaman engellerine ilişkin tesis/hizmet/ulaşım gibi engeller artarken buna paralel olarak fiziksel uygunluk stratejilerinin de arttı̆̆ını söylemek mümkündür. Daha genel bir yorum yapılacak olunursa serbest zaman engelleri artarsa, bireylerin bu engeller ile baş etme stratejilerinin arttıracağı ifade edilebilir. Araştırmaya ilişkin bu bilgi değerlendirildiğinde yapısal bir engel olan ve yaşanılan çevre içerisinde yer alan ve fiziksel aktivite yapmaya yönelik alan, saha ve olanakları ifade eden tesis/hizmet/ulaşım alt boyutu ve kişilerin mevcut sorumluluklar nedeniyle bir etkinliğe katılması önünde engel oluşturan unsurlar arttıkça; bu engelleri aşmaya yönelik olarak bireylerin fiziksel uygunluk ve beceri kazanım stratejilerini arttırmaları anlaşılır görülmektedir. Özellikle beceri kazanım stratejileri; bir etkinliğe katılmak için kampüs kaynaklarından yararlanma, hangi etkinliğe katılacağını öğrenebilme ve böylelikle planlama yapma becerilerini geliştirmeyi amaç edinen bir kavramdır. Bunun yanı sıra bireylerin, zaman yönetimlerini en doğru şekilde yapmaları ve böylelikle bir serbest zaman etkinliğine katılım sağlamaları da beceri edinimi gerektiren önemli hususlardan biridir. Bu durum ikinci kanonik değişkene en fazla katkı sunan zaman engeli ve bu engel ile baş edebilme stratejisi olarak beceri edinimi arasındaki ilişkiyi de açıklamaktadır.

Bununla birlikte üçüncü kanonik fonksiyona katkı sağlayan değişken çifti sosyal ortam ve finansal yönetim arasındaki ilişki de tartışmaya açıktır. Bireyin sosyal çevresinin sebep olduğu ve kişiler arası bir engel olan sosyal ortam alt boyutu puanları arttıkça bununla baş edebilmek için finansal yönetim becerilerinin artması şu şekilde açıklanabilir: White'ın 2008'de yaptığı bir çalışma da engeller, baş etme stratejileri, öz yeterlilik arasındaki ilişkiler değerlendirilmiştir. Araştırma önerilerinde içsel, dışsal ve yapısal engellerin birbiri ile ilişkili olabileceğine ilişkin öneriler bulunmaktadır. White’a (2008) göre örneğin, utangaçlık (içsel engel) veya maddi yetersizlik (yapısal engel) maliyeti paylaşmak ve duygusal destek sağlamak için katılıma bir arkadaş (kişiler arası engel) gerekliliği getirebilir. Bu noktada sosyal ortamın sebep olduğu engelleri, finansal yönetim becerileri ile çözebilmek derinlemesine bir araştırmayı gerektirmektedir.

\section{Sinırlılıklar}

Yapılan çalışma alanyazında sık kullanılmayan KKA ile yapılmıştır. KKA anlaşılması ve yorumlanması zor olan bir analiz olduğu için araştırmacılar tarafindan görece daha az tercih edilen bir analiz türüdür. Bu durum KKA ile yapılan çalışmaların ve bulguların sınırlı olmasına sebebiyet 
vermekte ve araştırmacıların KKA sonuçlarını tartışmak ve yorumlamak için ampirik kanıtlara ulaşmakta zorluk çekmesine neden olmaktadır. Bu çalışmada tartışmanın güçlü bir şekilde yapılabilmesi için başka araştırma sonuçlarına ihtiyaç duyulmasının ve benzer sonuçları veren çalışmaların olmamasının, araştırmanın en önemli sınırlılığı olduğu düşünülmektedir.

Serbest zaman alanyazında; serbest zaman katılımı için belirleyici olduğu düşünülen serbest zaman engelleri ve kişilerin bu engeller ile nasıl baş ettiklerini anlamak önemlidir. Özellikle bireylerin hangi engellere ne tür baş etme stratejileri geliştirdiği önemle araştırılması gereken konuların başında gelmektedir. KKA'nin bu anlamda keşifsel bir çalışma olması ve alanyazında kurulan hipotezleri test etmekten çok, fark edilmemiş daha güçlü ilişkilere odaklanması araştırmacılar için önemli bir boşluğu doldurmaktadır. Ancak bununla birlikte yeni tartışmalara ve bu tartışma sonuçlarının olası sebeplerini açıklamaya olan ihtiyaç da artmaktadır. Bu ihtiyacı karşılamak için hem KKA ile yapılan çalışmalar arttırılmalı hem de bir olguyu açıklarken neden ve nasıl sorularının yanıtlarına ulaşmayı hedefleyen nitel araştırmaların gerekliliği de vurgulanmalıdır. Dolayısı ile araştırmacıların daha sonraki aşamalarda KKA sonucunda çıkan bulgulardaki derinliği keşfedebilmek için nitel çalışmalar veya ilişkisel karma yöntem araştırmaları yapması, tartışmada yaşanan olası sıkıntıların giderilmesinde belirleyici olacaktır.

Sonuç olarak; alanyazında serbest zaman katılımı için belirleyici olduğu düşünülen serbest zaman engelleri ve bu engeller ile bireylerin nasıl baş ettiğine yönelik ilişkiyi inceleyen nicel araştırmaların artması ve bu ilişkinin olası sebeplerini derinlemesine bir şekilde incelenmesi için nitel çalışmaların da yapılması gerekmektedir.

\section{KAYNAKLAR}

Alexandris, K., \& Carroll, B. (1997). An analysis of leisure constraints based on different recreational sport participation levels: Results from a study in Greece. Leisure Sciences, 19, 1-15.

Alexandris, K., Kouthouris, C., \& Girgolas, G. (2007). Investigating the relationships among motivation, negotiation, and alpine skiing participation. Journal of Leisure Research, 39(4), 648-667.

Beggs, B.A., Elkins, D.J., \& Powers, S. (2005). Overcoming barriers to participation in campus recreational sports. Recreational Sports Journal, 29(2),143-155.

Bialeschki, M.D., \& Pearce, K.D. (1997). "I don't want a lifestyle-1 want a life": The effect of role negotiations on the leisure of lesbian mothers. Journal of Leisure Research, 29(1), 113-131.

Büyüköztürk, Ş., Çakmak, E.K., Akgün, Ö.E., Karadeniz, Ş., \& Demirel, F. (2014). Bilimsel Araştırma Yöntemleri. Ankara: Pegem Akademi.

Chen, S.F., Lou, S.J., \& Ma, S.M. (2018) Role of positive emotions in the constraint process: The case of Taiwanese college students. Leisure Studies, 37(5), 574-588.

Coble, T.G., Selin, S.W., \& Erickson, B.B. (2003). Hiking alone: Understanding fear, negotiation strategies and leisure experience. Journal of Leisure Research, 35(1), 1-22.

Crawford, D.W., \& Godbey, G. (1987). Reconceptualizing barriers to family leisure. Leisure Sciences, 9(2), 119-127. 
Yerlisu Lapa, T. ve Köse, E. (2018). Serbest zaman engelleri ile engellerle baş etme stratejileri arasındaki ilişkinin incelenmesi: Keşifsel bir çalışma. CBÜ Beden Ĕ̈itimi ve Spor Bilimleri Dergisi, 13(2), 356-375.

Crawford, D.W., Jackson, E.L., \& Godbey, G. (1991). A hierarchical model of leisure constraints. Leisure Sciences, 13(4), 309320.

Çakır, V.O., Şahin, S., Serdar, E., \& Parlakkılıç, Ş. (2016). Kamu çalışanlarının serbest zaman engelleri ile yaşam tatmini düzeylerinin incelenmesi. Journal of Tourism Theory and Research, 2(2), 135-141.

Çokluk, Ö., Şekercioğlu, G., \& Büyüköztürk, Ş. (2016). Sosyal Bilimler için Çok Değişkenli İstatistik Spss ve Lisrel Uygulamalart. (4.Bask1), Ankara: Pegem Akademi.

Dishman, R.K., Sallis, J.F., \& Orenstein, D.R. (1985). The determinants of physical activity and exercise. Public Health Reports, $100(2), 158-171$.

Elkins, D.J. (2004). Levels of perceived constraint: A comparative analysis of negotiation strategies in campus recreational sports. Unpublished Doctoral Thesis. Indiana University, Indiana.

Elkins, D.J., Beggs, B.A., \& Choutka, E. (2007). The contribution of constraint negotiation to the leisure satisfaction of college students in campus recreational sports. Recreational Sports Journal, 31(2), 107-118.

Gümüş, H., Ișık, Ö., Karakullukçu, Ö., \& Yıldırım, İ. (2014). Ortaöğretim kurumlarında serbest zaman fiziksel aktivite k1sitlayıc1ları. International Journal of Science Culture and Sport, Special Issue 1, 814-825.

Güner, B. (2015). Kadınların spor ve serbest zaman etkinliklerine katılım sorunlarının değerlendirilmesi. Uluslararası Spor Bilimleri Dergisi, 1(1), 22-29.

Gürbüz, B., Öncü, E., \& Emir, E. (2012). Boş zaman engelleri ölçeği: Yapı geçerliğinin test edilmesi, 12.Uluslararası Spor Bilimleri Kongresi, (s. 339-343), 12-14 Aralık, Denizli, Türkiye.

Hair, J.F., Black, W.C., Babin, B.J., \& Anderson, R.E. (1998). Multivariate Data Analysis. New Jersey: Prentice Hall Int. Inc.

Henderson, K.A. (1991). The contribution of feminism to an understanding of leisure constraints. Journal of Leisure Research, 23(4), 363-377.

Henderson, K.A., \& Allen, K.R. (1991). The ethic of care: Leisure possibilities and constraints for women. Society and Leisure, 14(1), 97-113.

Henderson, K.A., \& Bialeschki, M.D. (1993). Exploring an expanded model of women's leisure constraints. Journal of Applied Recreation Research, 18(4), 229-252.

Henderson, K.A., \& Dialeschki, M.D. (1991). A sense of entitlement to leisure as constraint and empowerment for women. Leisure Sciences, 13(1), 51-65.

Henderson, K.A., Bedini, L.A., Hecht, L., \& Schuler, R. (1995). Women with physical disabilities and the negotiation of leisure constraints. Leisure Studies, 14(1), 17-31.

Hubbard, J., \& Mannell, R.C. (2001). Testing competing models of the leisure constraint negotiation process in a corporate employee recreation setting. Leisure Sciences, 23(3),145-163.

Jackson, E. L. (2005). Leisure constraints research: Overview of a developing theme in leisure studies. In E. L. Jackson (Eds.). Constraints to leisure (pp. 3-19). State College, PA: Venture Pub., Inc.

Jackson, E.L. (1988). Leisure constraints: A survey of past research. Leisure Science, 10(3), 203-215.

Jackson, E.L. (1993). Recognizing patterns of leisure constraints: Results from alternative analyses. Journal of Leisure Research, 25(2), 129-149.

Jackson, E.L., \& Rucks, V.C. (1995). Negotiation of leisure constraints by junior-high and highschool students: An exploratory study. Journal of Leisure Research, 27(1), 85-105.

Jackson, E.L., Crawford, D. W., \& Godbey, G. (1993). Negotiation of leisure constraints. Leisure Sciences, 15, 1-11.

Kachigan, S. K. (1991). Multivariate Statistical Analysis: A Conceptual Introduction. New York: Radius Press.

Karaca, A.A., \& Yerlisu Lapa, T. (2016). Serbest zaman katılımı, psikolojik iyi olma ve serbest zaman engelleri ile baş etme stratejilerinin üniversite öğrencileri üzerinde incelenmesi. Journal of Human Sciences, 13(2), 3293- 3304.

Karaküçük, S., \& Gürbüz, B. (2007). Boş zaman engelleri ölçeği-28: Ölçek geliştirme, geçerlik ve güvenirlik çalışması. Gazi Beden Eğitimi ve Spor Bilimleri Dergisi, 1, 3-10.

Koca, C., Henderson, K.A., Asci, F.H., \& Bulgu, N. (2009). Constraints to leisure-time physical activity and negotiation strategies in turkish women. Journal of Leisure Research, 41(2), 225-251.

Köse, E. (2018). Denetimli serbestlik yasasından yararlanan bireylerin serbest zaman fiziksel aktivite katılım engellerine ilişkin bir durum çalışması. Uluslararası Rekreasyon ve Spor Yönetimi Kongresi, (s. 269-270), 10-13 Mayıs, Bodrum/Muğla, Türkiye.

Köse, E., \& Yerlisu Lapa, T. (2018). Denetimli serbestlik yasasından yararlanan bireyler: serbest zaman fiziksel aktivite k1sitlayıc1ları. Spormetre, 17(2), 119-137.

Little, D.E. (2000). Negotiating adventure recreation: How women can access satisfying adventure experiences throughout their lives. Loisir et societe/Society and Leisure, 23(1), 171-195.

Little, D.E. (2002). Women and adventure recreation: reconstructing leisure constraints and adventure experiences to negotiate continuing participation. Journal of Leisure Research, 34(2), 157-177.

Livengood, J.S., \& Stodolska, M. (2004). The effects of discrimination and constraints negotiation on leisure behavior of american muslims in the post-september 11 America. Journal of Leisure Research, 36(2), 183-208.

Loucks-Atkinson, A., \& Mannell, R.C. (2007). Role of self-efficacy in the constraints negotiation process: The case of individuals with Fibromyalgia syndrome. Leisure Sciences, 29, 19-36.

Ma, S.M., Tan, Y., \& Ma, S.C. (2002). Testing a structural model of psychological well-being, leisure negotiation, and leisure participation with Taiwanese college students. Leisure Sciences, 34(1), 55-71. 
Yerlisu Lapa, T. ve Köse, E. (2018). Serbest zaman engelleri ile engellerle baş etme stratejileri arasındaki ilişkinin incelenmesi: Keşifsel bir çalışma. CBÜ Beden Ĕ̈itimi ve Spor Bilimleri Dergisi, 13(2), 356-375.

Özşaker, M. (2012). Gençlerin serbest zaman aktivitelerine katılamama nedenleri üzerine bir inceleme. Selçuk Üniversitesi Beden Eğitimi ve Spor Bilimleri Dergisi, 14(1), 126-131.

Pinto, B., Marcus, B., \& Clark, M. (1996). Promoting physical activity in women: the new challenges. American Journal of Preventive Medicine, 12(5), 395-400.

Ravid, R. (1994). Pratical Statistics for Educators. Newyork: University Pres in America.

Samdahl, D.M., \& Jekubovich, N.J. (1997). A critique of leisure constraints: Comparative analyses and understandings. Journal of Leisure Research, 29(4), 430-452.

Scott, D. (1991). The problematic nature of participation in contract bridge: A qualitative study of group-related constraints. Leisure Sciences, 13(4), 321-336.

Shaw, S.M. (1994). Gender, leisure, and constraint: Towards a framework for the analysis of women's leisure. Journal of Leisure Research, 26(1), 8-22.

Shaw, S.M., Bonen, A., \& McCabe, J.F. (1991). Do more constraints mean less leisure? Examining the relationship between constraints and participation. Journal of Leisure Research, 23(4), 286-300.

Son, J.S., Mowen, A.J., \& Kerstetter, D.L. (2008a). Do age and gender matter in the constraint negotiation of physically active leisure? Journal of Leisure Research, 40(2), 267-289.

Son, J.S., Mowen A.J., \& Kerstetter, D.L. (2008b). Testing alternative leisure constraint negotiation models: An extension of Hubbard and Mannell's study. Leisure Studies, 30(3), 198-216.

Stanis, S.A., Schneider, I.E., Chavez, D.J., \& Shinew, K.J. (2009). Visitor constraints to physical activity in park and recreation areas: Differences by race and ethnicity. Journal of Park and Recreation Administration, 27(3), 78-95.

Temurtaş, A. (2016). Herkes için çok değişkenli istatistik. C.O. Güzeller (Eds) içinde. Kanonik korelasyon analizi (ss.102). Ankara: Maya Akademi.

White, D.D. (2008). A structural model of leisure constraints negotiation in outdoor recreation. Leisure Sciences, 30(4), $342-359$.

Yerlisu Lapa, T. (2014). Leisure negotiation strategies scale: A study of validity and reliability for university students. South African Journal for Research in Sport, Physical Education and Recreation, 36(3), 201-215.

Yerlisu Lapa, T., \& Haş1 Korkmaz, N. (2017). Fiziksel aktivite düzeyinin pozitif ve negatif duygu durumuna etkisinin cinsiyete göre karşılaştırılması: Akdeniz ve Uludağ Üniversiteleri örneği. Journal of Human Sciences, 14(4), 3177- 3187. 